

\section{DISCLAIMER}

This report was prepared as an account of work sponsored by an agency of the United States Government. Neither the United States Government nor any agency Thereof, nor any of their employees, makes any warranty, express or implied, or assumes any legal liability or responsibility for the accuracy, completeness, or usefulness of any information, apparatus, product, or process disclosed, or represents that its use would not infringe privately owned rights. Reference herein to any specific commercial product, process, or service by trade name, trademark, manufacturer, or otherwise does not necessarily constitute or imply its endorsement, recommendation, or favoring by the United States Government or any agency thereof. The views and opinions of authors expressed herein do not necessarily state or reflect those of the United States Government or any agency thereof. 


\section{DISCLAIMER}

Portions of this document may be illegible in electronic image products. Images are produced from the best available original document. 


\section{Printed in the United States of America. Available from}

National Technical Information Service

U.S. Department of Commerce

5285 Port Royal Road, Springfield, Virginia 22161

Price: Printed Copy $\$ 4.00$; Microfiche $\$ 3.00$

This report was prepared as an account of work sponsored by the United States Government. Neither the United States nor the Energy Research and Development Administration/United States Nuclear Regulatory Commission, nor any of their employees, nor any of their contractors, subcontractors, or their employees, makes any warranty, express or implied, or assumes any legal liability or responsibility for the accuracy, completeness or usefulness of any information, apparatus, product or process disclosed, or represents that its use would not infringe privately owned rights. 
Contract No. W-7405-eng-26

Neutron Physics Division

\title{
HADRONIC- AND ELECTROMAGNETIC-CASCADE DISCRIMINATION \\ IN A THIN LEAD-ARGON CALORIMETER*
}

\author{
$T$. Jensen \\ Department of Physics and Astronomy \\ University of Rochester \\ Rochester, NY, 14627
}

J. D. Amburgey ${ }^{\dagger}$

T. A. Gabriel

Note:

Partially funded by the University of Rochester under Contract No. EY-76-C-02-3065 with the Energy Research and Development Administration

Date Published - February 1977

*Submitted for journal publication.

tComputer Sciences Division.

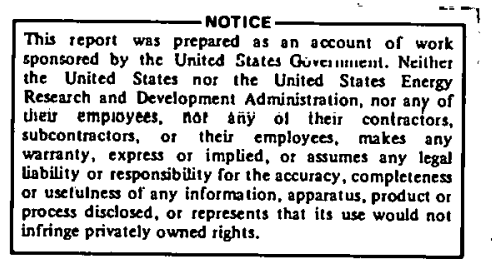

NOTICE This document contains information of a preliminary nature.

It is subject to revision or correction and therefore does not represent a

final report.

OAK RIDGE NATIONAL LABORATORY

Oak Ridge, Tennessee, 37830

operated by

UNION CARBIDE CORPORATION

for the

ENERGY RESEARCH AND DEVELOPMENT ADMINISTRATION 
THIS PAGE

WAS INTENTIONALLY

LEFT BLANK 


\section{Abstract}

Calculations have been carried out to determine methods or a combination of methods for discriminating between high-energy ( $>15 \mathrm{GeV}$ ) hadrons and leptons or photons incident on a thin lead-argon calorimeter. Some of the methods considered involve fluctuations in shower development, the centroid of the shower, and ratios of the pulse height obtained from various locations within the device. Of these, the latter appears the most promising. 


\section{THIS PAGE WAS INTENTIONALLY LEFT BLANK}




\section{Acknowledgments}

We wish to thank Drs. F. Lobkowicz and T. Ferbel for many helpful discussions. 


\section{INTRODUCTION}

Calorimetric discrimination between incident hadrons and leptons or photons is a challenging and often frustrating problem that has to be solved for many experimental setups. Unfortunately, no one solution is applicable in all situations due to the wide diversity of calorimeter design. Presented in this paper is a series of calculations in which several different approaches have been taken to solve this problem for a thin $[27$ radiation lengths (r.l.), 1.24 interaction lengths (i.1.)] lead-argon calorimeter. These types of calorimeters, whose theory and design are well documented ${ }^{1-5}$ ), are proving to be very versatile and accurate devices for measuring the position and energy of the hadrons, leptons, and photons.

The particular device considered in this work is to be used at the Fermi National Accelerator Laboratory in a mixed particle field to detect photons in the energy range of 10 to $100 \mathrm{GeV}$ and specifically those photons that result from the decay of neutral pions produced through dissociation processes $\left.{ }^{6}\right)$. For comparison with a more conventional shower detector, calculations were also carried out for hadrons incident on a lead-plastic scintillator detector of the Caltech variety ${ }^{7}$ ).

In sect. 2 the geometry of the calorimeters and the methods of calculation are described and in sect. 3 the results are presented and discussed.

\section{GEOMETRY AND CALCULATIONAL METHODS}

As shown in fig. 1 , the calorimeter has a total of 70 unit cells, each consisting of a 2-mm lead plate, a 1-mm gap for liquid argon, a 1/16-in.thick sheet of G-10 (see table 1) having copper readout strips $1 \mathrm{~cm}$ wide etched on both sides (one for $x$ and one for $y$ ), and a second 1-mm gap for liquid argon. The cross-sectional area of the calorimeter is $70 \times 70 \mathrm{~cm}^{2}$. 


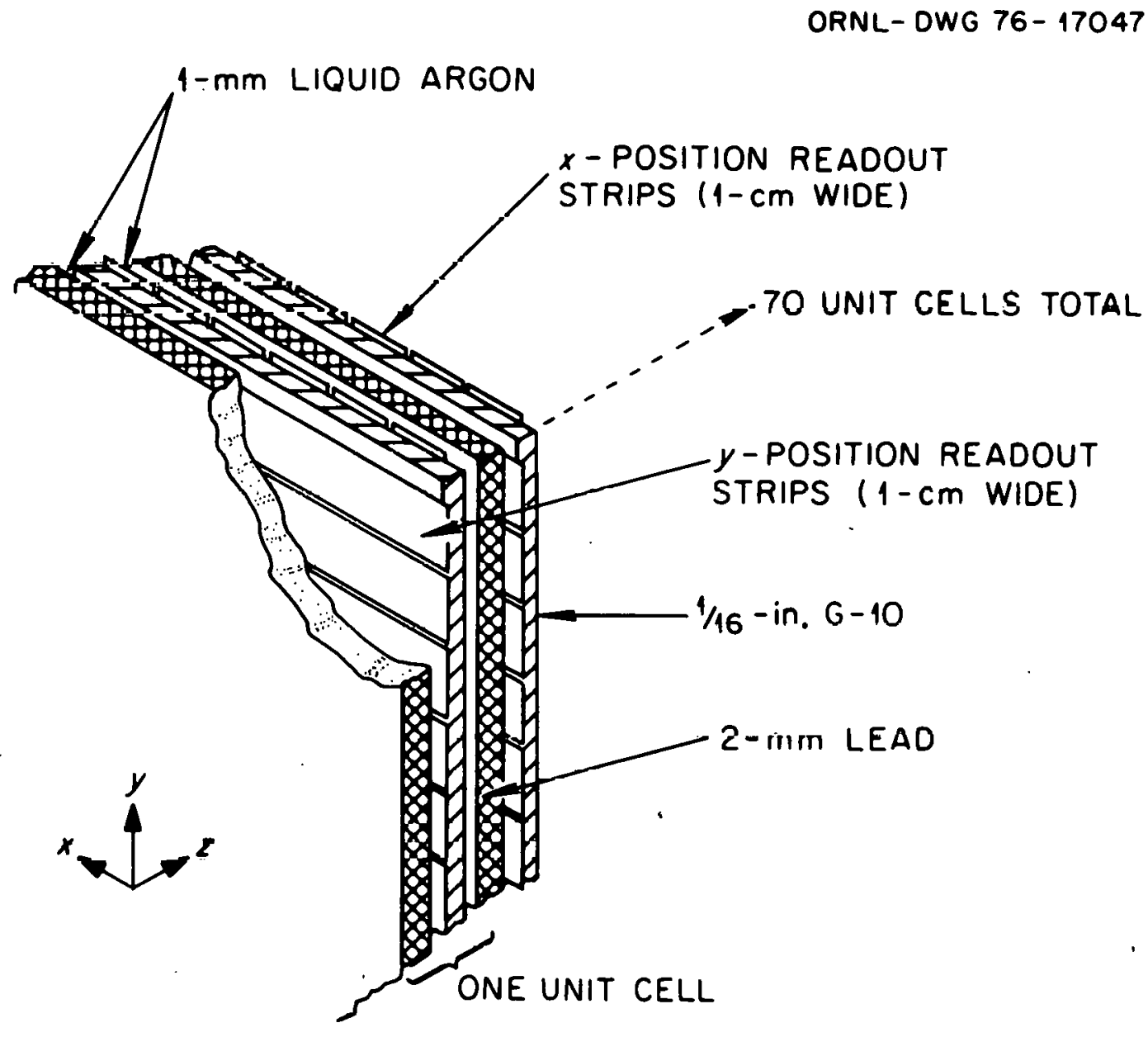

Fig. 1. Schematic diagram of the lead-argon calorimeter used in the Montc Carlo calculations. 
The properties of the materials used in this detector are given in table 1. A depth of $\sim 27$ r.1. was chosen so as to contain (within a few percent) a 100-GeV photon shower. However, this amount of material is $\sim 1.24-i .1$. thick, so that the number of interactions of hadrons in the detector is substantial.

The lead-plastic design is essentially that of the (altech detector ${ }^{7}$ ), with $0.25-i n$. lead plates separating alternate $x$ and $y$ planes of 0.25 -in.thick by $1-\mathrm{cm}$-wide scintillator fingers for a total of $10 \times$ and $10 \mathrm{y}$ planes. This detector has a total of $23 \mathrm{r} .1$. and $0.9 \mathrm{i} .1$.

The calculational procedures employed for obtaining detailed descriptions of the three-dimensional hadronic and electromagnetic cascades within multimedia calorimeters have been described previously ${ }^{8}$ ) and will not be discussed here. It is sufficient to state that the code system has been compared many times with different experimental data and reasonable agreement has been obtained ${ }^{8}$.

\section{RESULTS}

Using the simple attenuation law $N(z)=N_{0} \exp (-z / \lambda)$, it is expected that $\sim 30 \%$ of the incident hadrons will pass through the detector without interacting. This is verified in table 2 for incident protons. Since the energy deposited by a minimum ionizing particle may be at about the noise level of the readout electronics, these particles will not be considered in the results to follow unless explicit remarks are made to the contrary.

The total energy deposited* in argon by hadrons and electrons is shown in fig. 2. Since there is not enough material in the detector to fully develop a hadronic shower, there are large fluctuations in the total energy deposited by hadrons. Electrons deposit $\sim 9.5 \%$ of their energy in the argon

\footnotetext{
*The words "energy deposited" and "pulse height" will be used to mean the same thing.
} 
Table 1

Properties of Materials Used in the Calorimeter

\begin{tabular}{ccccccc}
\hline Material & $\begin{array}{c}\text { Minimum } \\
\text { Density } \\
\left(\mathrm{g} / \mathrm{cm}^{3}\right)\end{array}$ & $\begin{array}{c}\text { Enization } \\
(\mathrm{MeV} / \mathrm{cm})\end{array}$ & $\begin{array}{c}\text { Radiation } \\
\text { Length } \\
(\mathrm{cm})\end{array}$ & $\begin{array}{c}\text { Number of } \\
\text { Radiation } \\
\text { Lengths }\end{array}$ & $\begin{array}{c}\text { Inter- } \\
\text { action } \\
\text { Length } \\
(\mathrm{cm})\end{array}$ & $\begin{array}{c}\text { Number of } \\
\text { Inter- } \\
\text { action } \\
\text { Lengths }\end{array}$ \\
\hline $\mathrm{Pb}$ & 11.35 & 12.8 & 0.56 & 25.0 & 18.5 & 0.76 \\
L1qu1d $\mathrm{A}$ & 1.4 & 2.2 & 13.5 & 1.0 & 65.0 & 0.22 \\
$\mathrm{G}-10^{\mathrm{a}}$ & 1.9 & 3.2 & 12.6 & 0.9 & 42.0 & 0.26 \\
\hline \hline
\end{tabular}

a. For lack of better information, G-10 was assumed to be an equal atomic mixture of $\mathrm{H}, \mathrm{Al}$, and $\mathrm{C}$. 
Table 2

Minimum Ionizing Protons

\begin{tabular}{ccc}
\hline $\begin{array}{c}\text { Energy } \\
(\mathrm{GeV})\end{array}$ & $\begin{array}{c}\text { Fraction of } \\
\text { Incident Protons } \\
\text { Not Interacting } \\
(\%)\end{array}$ & $\begin{array}{c}\text { Energy Deposited } \\
\text { in Argon } \\
(\mathrm{MeV})\end{array}$ \\
\hline 50 & $26 \pm 4$ & $47.8 \pm 0.5$ \\
150 & $25 \pm 5$ & $54.8 \pm 0.6$ \\
250 & $35 \pm 6$ & $79.9 \pm 0.8$ \\
\hline
\end{tabular}



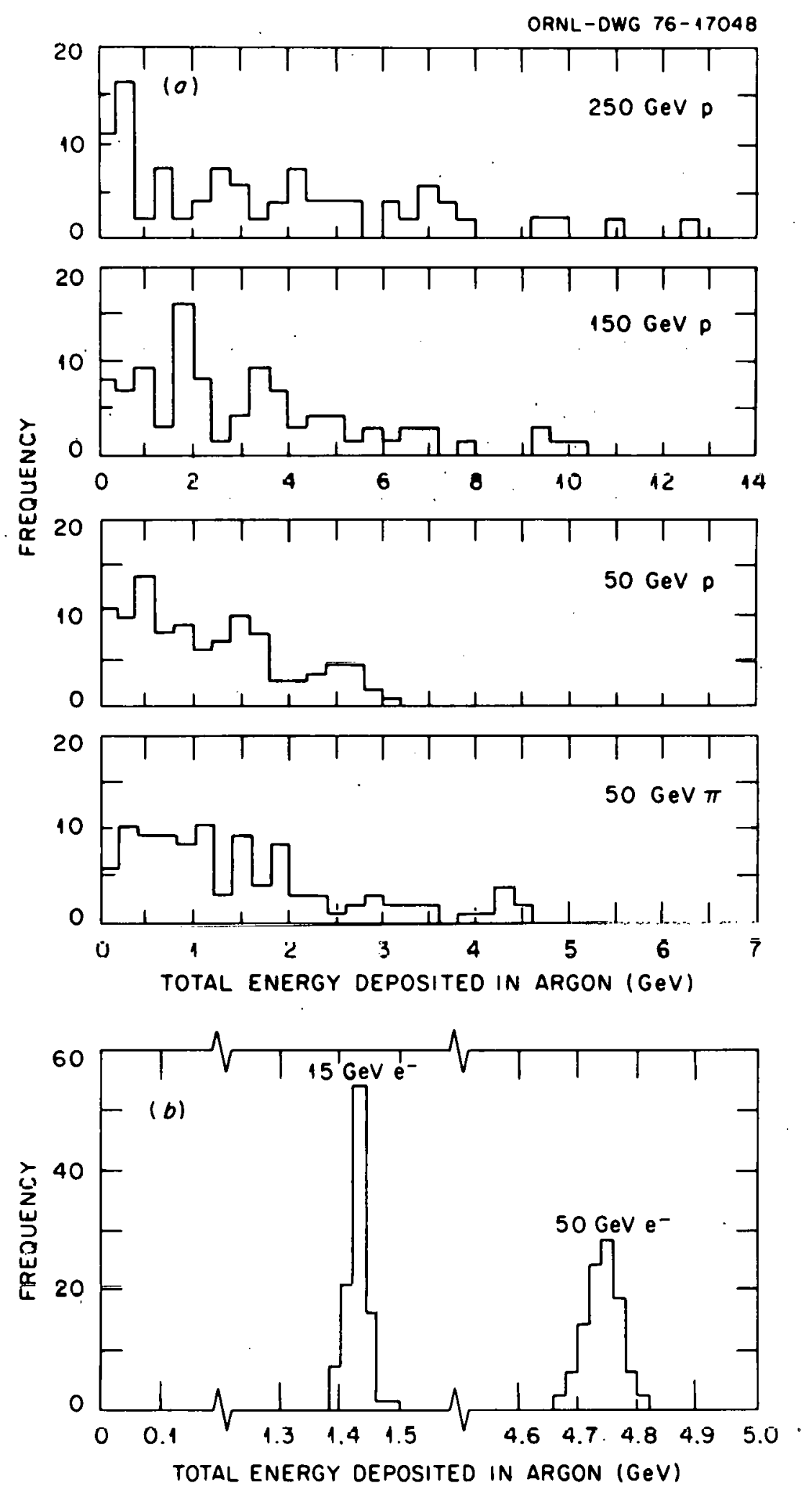

Fig. 2. Pulse height for (a) incident hadrons which interact in the detector and (b) incident electrons. All curves have been normalized to 100 counts (statistics for the high-energy particles are poorest). 
for incident momenta from 15 to $50 \mathrm{GeV} / \mathrm{c}$. The energy resolution in this range is $\sim 10 \% / \sqrt{E(G e V)}$ full width at half maximum (FWHM) - this is for the ideal case of total charge collection and no noise. A prototype lead-argon calorimeter has been tested in an electron beam with momenta up to $10 \mathrm{GeV} / \mathrm{c}^{9}$ ). This detector is $\sim 14.7 \mathrm{r} .1$. thick and uses a $1.2-\mathrm{mm}$ argon gap. The results of this test give an intrinsic energy resolution $\Delta E / E \approx 27 \% / \sqrt{E}$ FWHM which is much worse than the above Monte Carlo, results. However, if Monte Carlo data from only the front half ( 13.5 r.l.) of the calorimeter are used, the predicted resolution is $37 \% / \sqrt{E}$ FWHM. This emphasizes the necessity of containing the electromagnetic shower. For the whole calorimeter, $\sim 4 \%$ of the energy leaks out, whereas for the front half 15\% escapes. From these results, it can be concluded that electron/hadron discrimination based on the total pulse height is feasible for only narrow ranges of electron energies.

Figure 3 shows the average lateral energy deposition for both hadrons and electrons. Considering that the threshold for firing a strip (integrated over the $z$ direction) will be at least the minimum ionizing level ( 50-100 MeV), it is clear that high-energy hadron showers are very similar in character to low-energy electron showers. The fact that hadron showers do not spread too much will be an asset when it comes to subtracting off-line these showers from the desired photon or electron showers. For the case of charged hadrons, information will be available experimentally on particle trajectories upstream of the shower detector. Figure 4 shows how accurately positions of incident hadrons can be determined in the detector. These results were obtained by taking an energy-weighted sum of the strip positions ${ }^{4,10}$ ); i.e.,

$$
\langle x\rangle=\sum_{i, j} x_{i} E_{i j}^{x} / \sum_{i, j} E_{i j}^{x},
$$


ORNL-DWG 76-17049

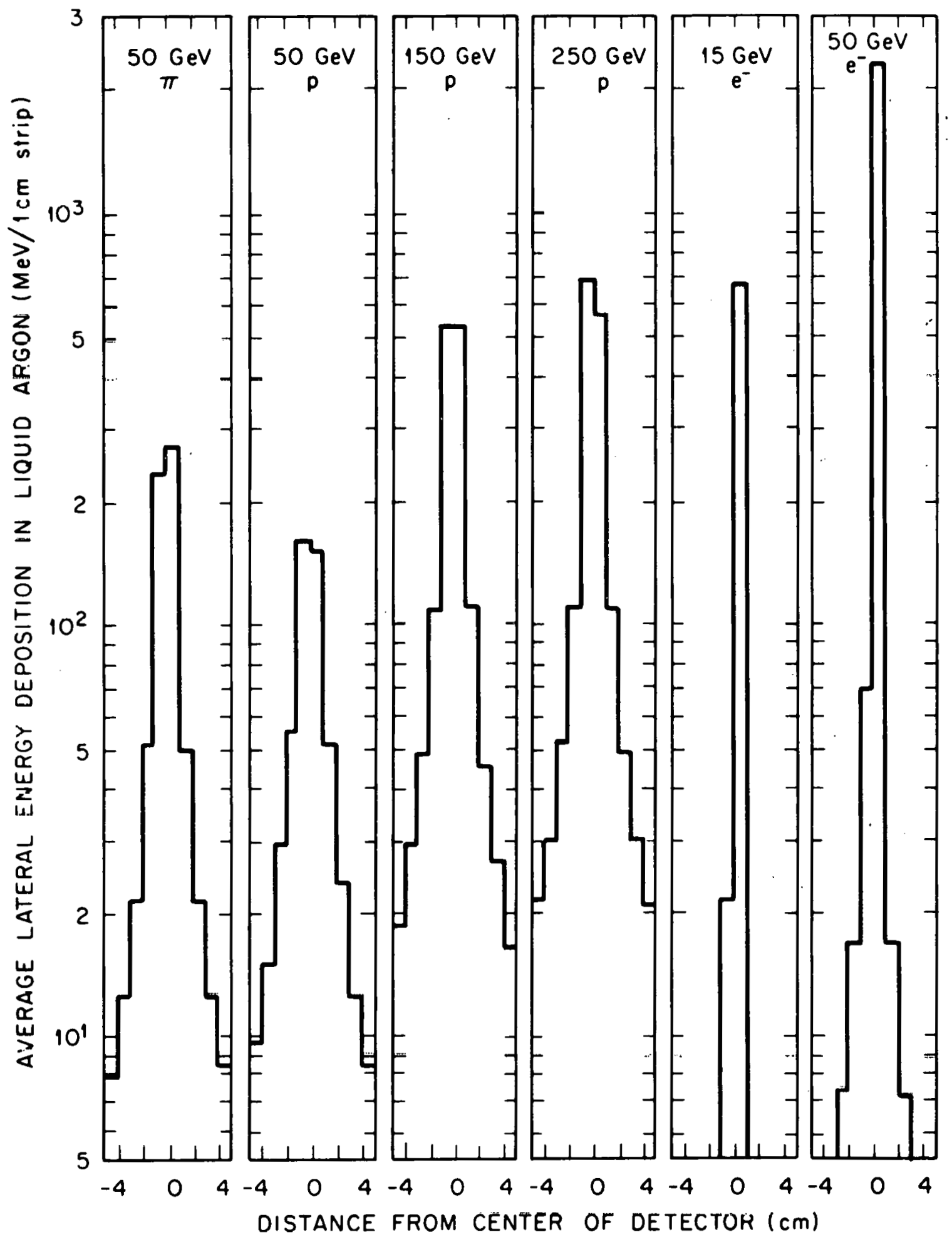

Fig. 3. Average lateral spread of showers. The energy deposited in each $7-\mathrm{cm}$ strip is summed over the $z$ direction, and in the averaging, both $x$ and $y$ strips were combined due to the symmetry expected for a particle incident at the center of the detector. The curves for incident hadrons include only those that interacted in the detector. 


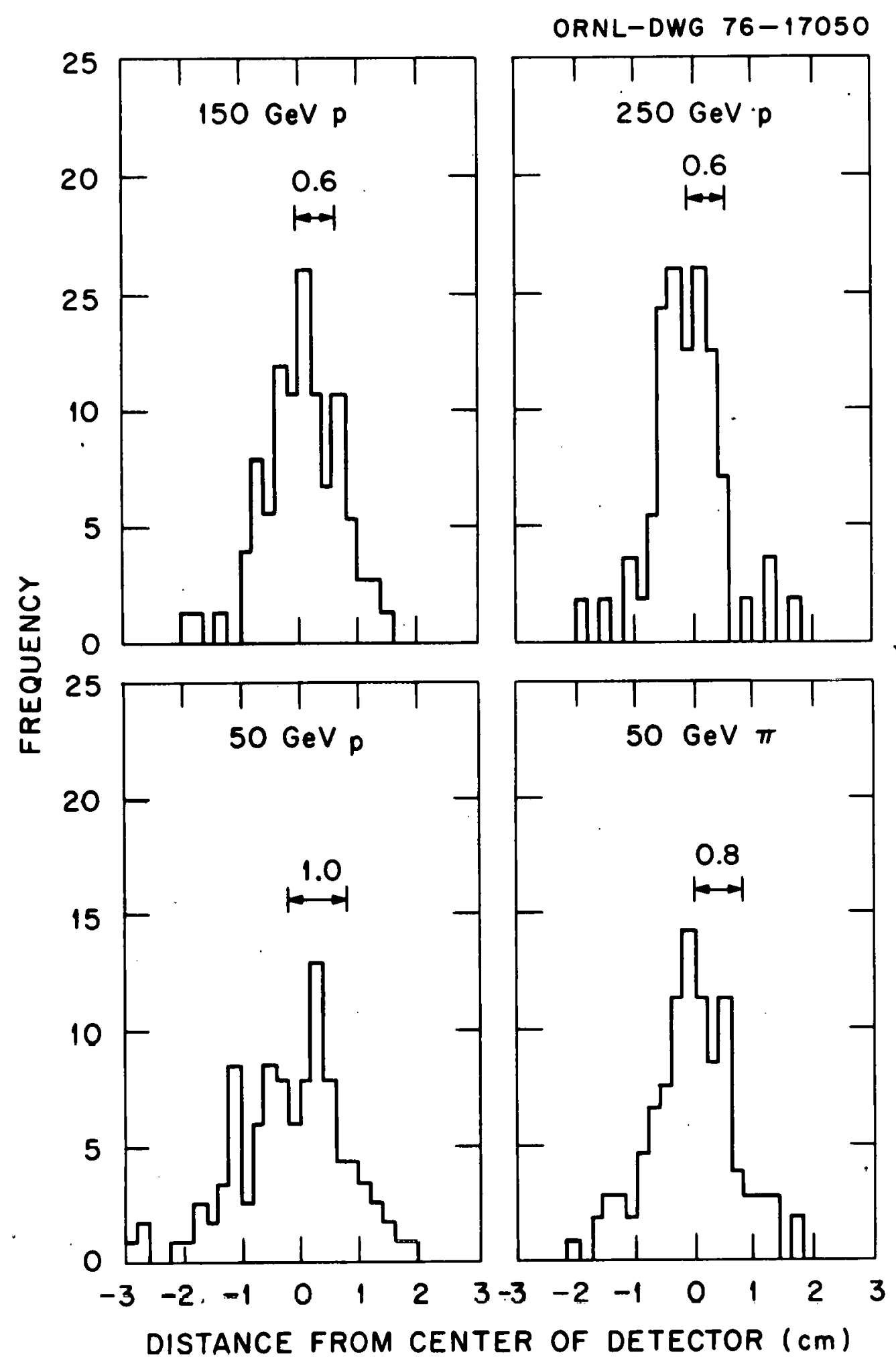

Fig. 4. Dispersion of hadron position as determined by Eq. (1). Only interacting hadrons were considered, and each curve has been normalized to 100 counts. 
where $x_{i}$ is the position of the center of the $i$ th strip and $E_{i j}^{x}$ is the energy deposited in this strip in the $j$ th unit cell. A similar expression is used to determine the $y$ position. The results indicate $\sigma\langle x\rangle<1 \mathrm{~cm}$ for hadrons.

Figure 5 displays the basis for electron/hadron discrimination through differences in longitudinal energy deposition. Electron showers peak at $\sim 6-8$ r.1., whereas a hadron shower is still in an early stage of development throughout the entire calorimeter. As a measure of the fluctuations, the level of rms deviation from the mean is indicated on these figures (i.e., the solid curves are for $\bar{E}+\sigma\langle\bar{E}\rangle)$.

Various hadron-rejection schemes based on the longitudinal shower shape were tested. The simplest method (and the one most amenable to triggering needs) is to look at the pulse height from a given region of the detector. This, however, is quite crude as fig. 6 shows. A factor of 5-10 reduction in hadron background (above the minimum ionizing level) may be obtained by cutting on the pulse height in the first five or so radiation lengths, but this will also result in $>10 \%$ electron 1osses, with a strong bias against low-energy electrons. Using the signal from the region at about the peak of an electron shower gives comparable rejection and somewhat fewer losses, though still biasing strongly against lower energy electrons.

The really significant difference between the two showers is the slope of the longitudinal curve beyond the first quarter of the detector. A very efficient hadron-rejection scheme based on this observation is shown in fig. 7. Here the pulse height in the peak region of the electron shower is compared with the pulse height at the back of the detector. The results from all incident hadrons were combined and analyzed according to the total 


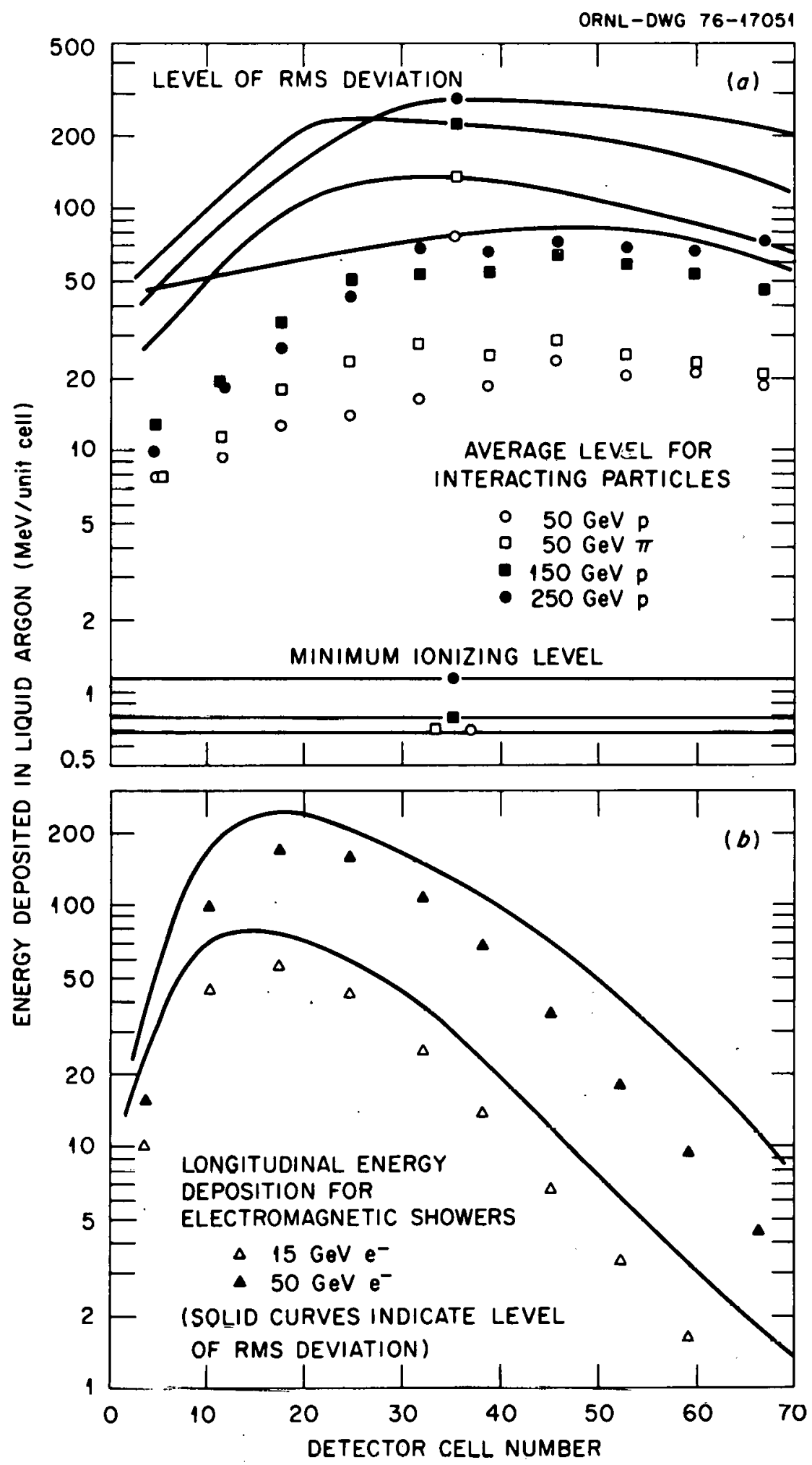

Fig. 5. Longitudinal shower curves for (a) incident hadrons and (b) incident electrons. The energy deposited in a unit cell is shown as a function of depth in the detector, cell 0 corresponding to the front of the detector. The solid curves indicate the rms deviation from the mean values. For hadrons the minimum ionizing level is also indicated. 


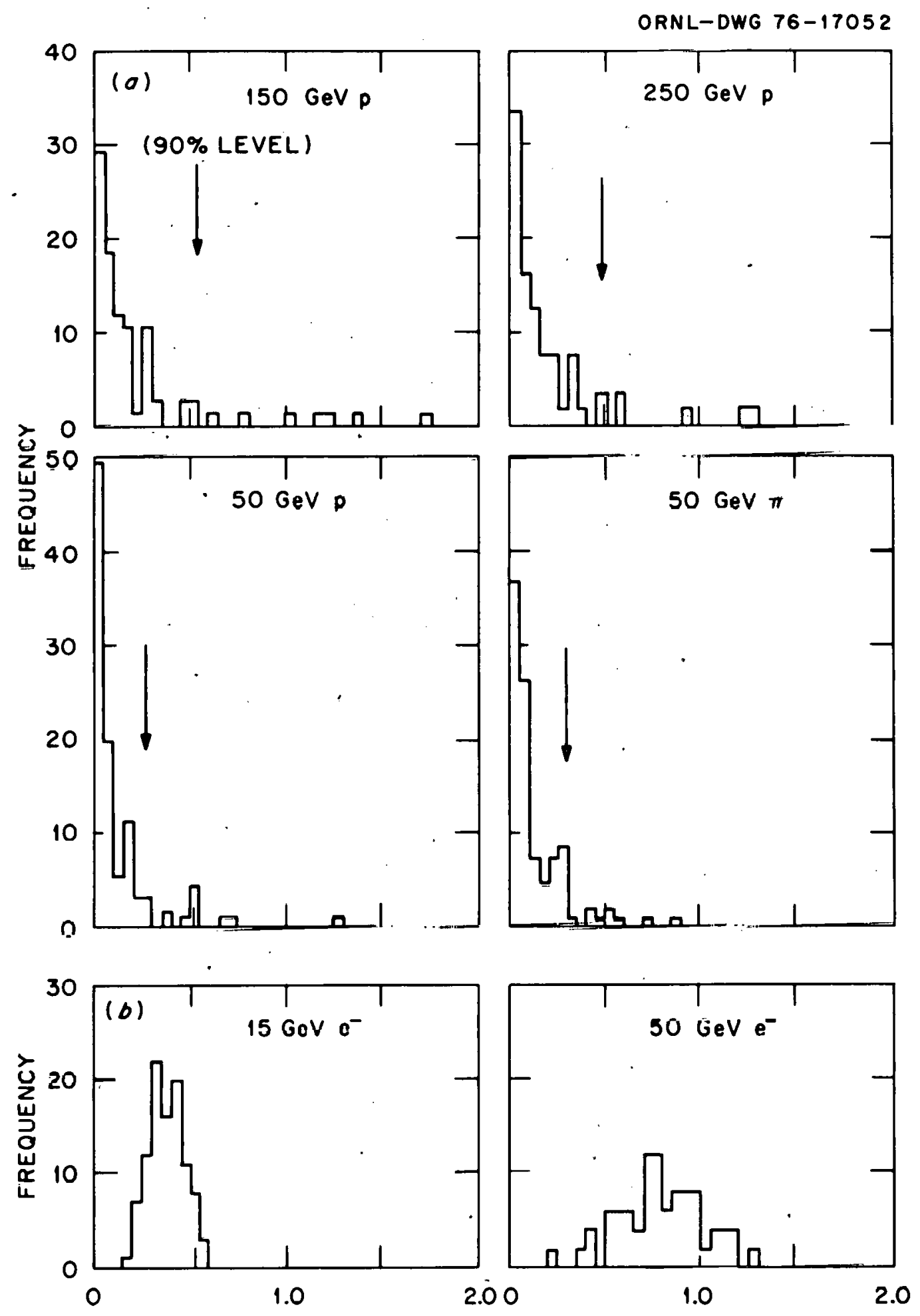

Fig. 6. Pulse height in the front 14 cells for (a) incident hadrons interacting in the detector and (b) incident electrons. All curves are normalized to 100 counts. The arrows in (a) indicate the level at which the hadronic signal is down by a factor of 10 . 


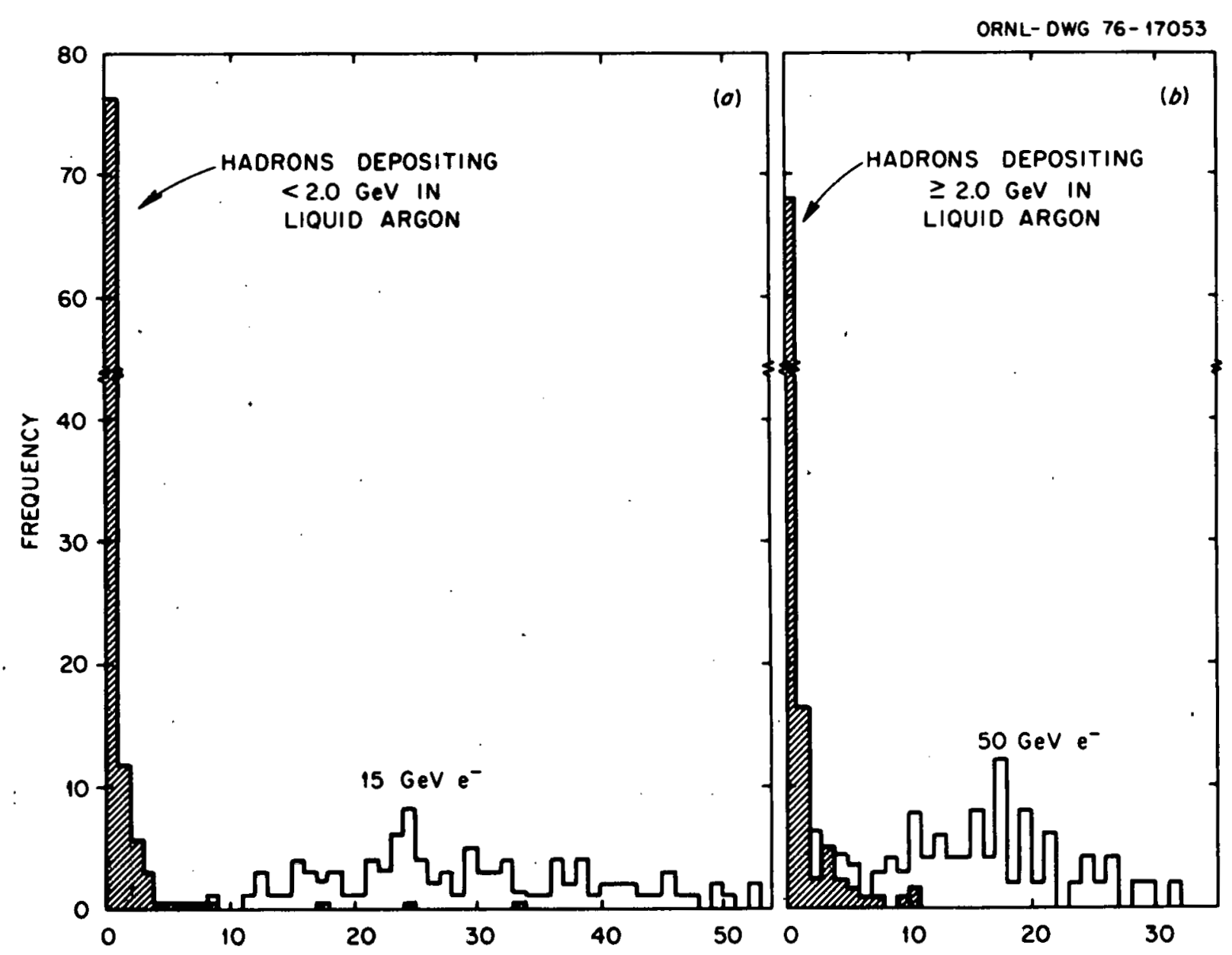

Fig. 7. An efficlent scheme for electron/hadron discrimination compares the pulse height at the peak of the electron shower to the pulse height at the back of the detector. In (a) hadrons depositing $<2 \mathrm{GeV}$ are compared with 15-GeV electrons (minimum ionizing hadrons have been removed), and in (b) hadrons depositing $\geq 2 \mathrm{GeV}$ are compared with 50-GeV electrons. 
energy deposited in the argon. Those hadrons depositing $<2 \mathrm{GeV}$ are compared with 15-GeV electrons and those depositing $\geq 2 \mathrm{GeV}$ are compared with 50-GeV electrons. The efficiency for low-energy electrons is excellent in this scheme, while high-energy electrons will suffer some losses. The statistics are too poor to determine what exact division of the detector is optimal, but it seems clear that the ratio of the pulse height near the peak of the electron shower to that at the back of the detector would be an excellent indicator of the nature of the shower. For low-energy electrons, it should be possible to obtain at least a factor of 50 rejection with $<2 \%$ losses, whereas for high-energy electrons a factor of 20 in rejection with $48 \%$ losses is quite feasible.

Monte Carlo results for $50-$ and $150-\mathrm{GeV}$ protons incident on a leadplastic calorimeter (described in sect. 2) were compared with the lead-argon results. The lateral spread and determination of position were comparable though somewhat poorer in the lead-plastic design due to the increase in the sampling fluctuations. Although plastic scintillator inherently has a faster response time, the lead-argon design, particularly with methane doping to speed up drift times, should be quite adequate for a large aperture experiment with $\sim 10^{5}$ interactions/sec. The lead-argon calorimeter is obviously much more versatile when it comes to dividing the detector into longitudinal sections (which is necessary for good hadron rejection). This, plus better energy resolution, makes a lead-argon calorimeter the best choice when hadron rejection is important. 


\section{REFERENCES}

1J. Engler et al., Nucl. Instr. Meth. 120, 157 (1974).

2W. J. Willis and V. Radeka, Nucl. Instr. Meth. 120, 221 (1974).

${ }^{3}$ G. Knies and D. Neuffer, Nuc 1. Instr. Meth. 120, 1 (1974):

${ }^{4}$ T. A. Gabriel and W. Schmidt, Nucl. Instr. Meth. 134, 271 (1976).

${ }^{5}$ D. Hitlin et al., "Test of a Lead-Liquid-Argon Electromagnetic Shower Detector," preprint, Stanford Linear Accelerator Center and Lawrence Berkeley Laboratory (1975).

6P. Koehler et al., "Proposal to Measure Coherent Dissociation of $\pi^{-}, \mathrm{K}^{-}$, and $\overline{\mathrm{p}}$ into Two-Body Systems at Fermilab Energies," Fermilab Proposal E-272 (Revised) (1975).

${ }^{7}$ See, for example, R. A. Johnson, "Measurement of the $\pi^{-} p \rightarrow \pi^{\circ} n$ and $\pi^{-} p \rightarrow \eta n$ Differential Cross Sections at Beam Momenta from $20-200 \mathrm{GeV} / \mathrm{c}, "$ Thesis, Lawrence Berkeley Laboratory, University of California (1975). ${ }^{8}$ See Ref. 4 and the references therein.

9Y. Fukushima, "Argon Counter," Technical Note \#8, University of Rochester (1976).

${ }^{10} \mathrm{R}$. L. Walker, "Identification of $\pi^{\circ}, n$, and $x^{\circ}, "$ Internal Report No. 59, CALT-68-330, California Institute of Technology (1971). 
THIS PAGE

\section{WAS INTENTIONALLY LEFT BLANK}


ORNL/TM-5679

\section{Internal Distribution}

1-2. L. S. Abbott

3. F. S. Alsmiller

4. R. G. Alsmiller, Jr.

5-9. J. D. Amburgey

10. H. W. Bertini

11-25. T. A. Gabriel

26. F. C. Maienschein

27. F. R. Mynatt

28. E. M. Oblow

29. R. W. Roussin

30. RSIC

31. R. T. Santoro

32. M. L. Tobias
33. C. R. Weisbin

34. G. E. Whitesides

35. A. Zucker

36. P. Greebler (Consultant)

37. W. W. Havens, Jr. (Consul tant)

38. A. F. Henry (Consultant)

39. R. E. Uhrig (Consultant)

40-41. Central Research Library

42. ORNL Y-12 Technical Library, Document Reference Section

43. Laboratory Records Department

44. Laboratory Records, ORNL R.C.

45. ORNL Patent Office

\section{External Distribution}

46. E. D. Bloom, Stanford Linear Accelerator Center, P. O. Box 4349, Stanford, CA 94305.

47. C. Fabjan, CERN, Geneva 23, Switzerland.

48. G. Feldman, Stanford Linear Accelerator Center, P. O. Box 4349, Stanford, CA 94305.

49. W. T. Ford, Fermi National Accelerator Laboratory, P. O. Box 500, Batavia, IL 60510.

50. H. Goldstein, Columbia University, 287A Mudd Building, New York, NY 10027.

51. D. Hitlin, Stanford Linear Accelerator Center, P. O. Box 4349, Stanford, CA 94305.

52-62. T. Jensen, Department of Physics and Astronomy, University of Rochester, Rochester, NY 14627.

63. J. Kirkby, Stanford Linear Accelerator Center, P. O. Box 4349, Stanford, CA 94305.

64. L. Litt, Department of Physics, Michigan State University, East Lansing, MI 48823.

65. W. Schmidt, Institute of Experimental Nuclear Physics, University of Karlsruhe, 75 Karlsruhe, Germany.

66. A. L. Sessoms, Department of Physics, Harvard University, Cambridge, MA 02138.

67. L. R. Sulak, 252 Jefferson Laboratory, Harvard University, Cambridge, MA 02138.

68. W. J. Will is, CERN, Geneva 23, Switzerland.

69-95. Technical Information Center (TIC).

96. U.S. ERDA Oak Ridge Operations, Research and Technical Support Division, P. O. Box E, Oak Ridge, TN 37830: Director.

97-127. Given High-Energy Accelerator Shielding distribution. 